\title{
Health challenges in South African automotive companies: Wellness in the workplace
}

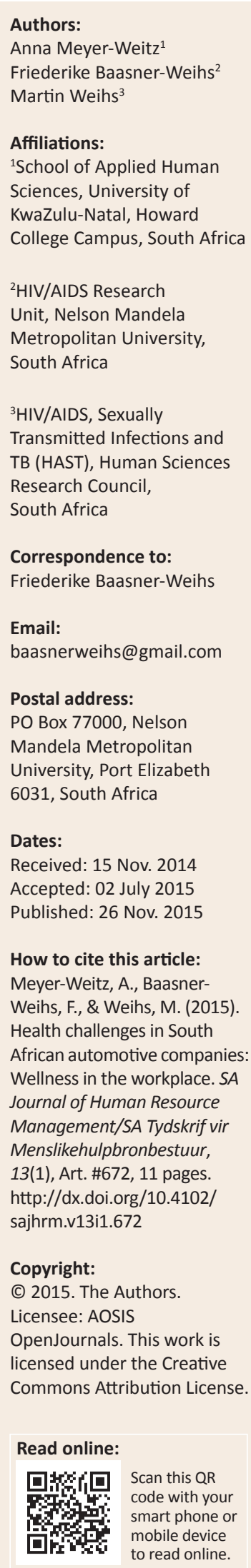

Orientation: In South Africa, workplace programmes in the automotive industry focus predominantly on occupational health and safety and HIV and AIDS. The implementation of focused workplace interventions might be hampered when companies are not convinced that the condition (i.e. HIV and AIDS) is the main negative health influencing factor responsible for increased production costs.

Research purpose: The study investigated the health influencing conditions perceived to negatively impact company production costs and related interventions.

Motivation for the study: Apart from HIV and AIDS, little information is available about the health challenges in the South African workplace and focused HIV and AIDS programmes might only partly respond to the key health challenges of workplaces. The inter-relatedness of various risky lifestyle factors linked to health conditions necessitates a comprehensive health promotion approach.

Research approach, design and method: A cross-sectional survey was conducted amongst 74 companies selected through stratified random sampling. Non-parametric tests were conducted to investigate the health influencing factors perceived to impact production costs, the monitoring thereof, extent of containment and the implementation of interventions in terms of company size and ownership.

Main findings: The health factors perceived to have a moderate to large impact were HIV and AIDS, smoking, alcohol use, stress, back and neck ache and tuberculosis, also reported to be better monitored and managed by medium and large organisations. Small organisations reported a smaller impact, fewer efforts and less success. HIV and AIDS programmes were more evident in large companies and those with wellness programmes (52\%). Workplace programmes enabled better monitoring and managing of impacting health conditions. Smaller organisations were not convinced of the benefits of interventions in addressing health challenges.

Practical/managerial implications: As the impacting health conditions seemed linked, comprehensive and integrated wellness programmes are required to address the health issues and ensure organisations' competitiveness.

Contribution: The results contribute to a better understanding of the perceived salient health influencing factors that impact on production costs. Data support the inter-relationships between the identified health concerns and call for more holistic wellness programmes.

\section{Introduction}

A healthy, well-trained, highly qualified and motivated workforce is critical for organisations' competitiveness in the global market. The workplace has been identified and has become a key health-promoting setting worldwide with corporate strategies and interventions directed at enhancing employees' health and well-being (Burton, 2010; Dornan \& Jane-Llopis, 2010; ILO, 2009; Van Wyngaardt, 2010). In most countries, workplace wellness-promoting strategies focus on health and safety, lifestyle and psychosocial factors (Burton, 2010). In South Africa, health matters in the workplace are regulated by a predominant labour approach to occupational health and safety as outlined by the Occupational Health and Safety Act (No. 85 of 1993). The HIV and AIDS pandemic however has necessitated a more public health approach to health matters as more focused HIV and AIDS initiatives are required and encouraged by the International Labour Organisation's Recommendation 200 (ILO, 2010). It is argued that company initiatives can slow down the HIV infection rate and reduce human suffering by improving knowledge regarding HIV and AIDS and tuberculosis (TB), facilitate access to HIV counselling and testing (HCT) and the timely support and treatment of HIV-infected employees and their partners (Department of Labour, 2000, 2012). The South African private sector, various corporate structures like the South 
African Business Coalition on Health and AIDS (SABCOHA), the Automotive Industry Development Centre Eastern Cape (AIDC EC) and international donor organisations responded by advocating and supporting the implementation of HIV and AIDS workplace programmes (HAWPs). Strong support was developed for the integration of HAWPs into broader workplace wellness programmes (WWPs) (SABCOHA, 2012). Workplace wellness is currently high on the Southern African Development Community's (SADC) agenda and reporting on health initiatives as part of companies' statutory reporting is being discussed as it is considered to be beneficial to businesses and socioeconomic development (Mail \& Guardian, 2015).

\section{Purpose}

Whilst many South African organisations have responded to the challenges posed by the HIV epidemic by implementing HAWPs, others have been slow to respond. The automotive component manufacturing sector seems to face challenges in this regard. One important factor might be perceptions that a workplace programme only focusing on HIV and AIDS is unlikely to successfully address their health challenges. According to the Healthy Company Index, a study conducted by Discovery in 2014 amongst 151 South African companies in partnership with the University of Cambridge and RAND Europe, the three most prevalent health concerns reported by employers are stress, blood pressure and cholesterol, whilst employees' most prevalent chronic diseases are high blood pressure, depression and diabetes (Discovery, 2014). Although the importance of addressing HIV and AIDS in the workplace is widely supported and governed by guidelines and policies, it is likely that the implementation of HAWPs is hampered when companies are not convinced that HIV and AIDS is the main negative health influencing factor responsible for increased production costs. The question arises whether comprehensive wellness programmes addressing various negative health influencing factors impacting organisations' production costs would not be considered more acceptable whilst simultaneously also providing the necessary platform to address HIV and AIDS. Little is however known of the health conditions perceived to negatively impact production costs of companies in the automotive sector.

The aim of this descriptive study was therefore to gain a better understanding of the health conditions perceived to negatively influence the production costs of South African companies in the automotive manufacturing sector and their related responses to enable a more informed view of appropriate responses to their health challenges. Ethical clearance for the study was obtained from the Ethics Committee of the University of KwaZulu-Natal (HSS/1424/010M).

\section{Literature review}

The World Health Organization (WHO) considers workplace health programmes as one of the best-buy options for prevention and control of noncommunicable diseases and for mental health (WHO, 2015). However, HIV and AIDS remains a key focus in workplaces globally as organisations have an economic interest and a moral obligation to engage in the prevention of HIV and AIDS, ensure access to support and treatment, whilst also ensuring a safe work environment free from HIV and AIDS stigma and discrimination (ILO, 2010). Despite the relative stability of the HIV and AIDS pandemic in South Africa over the last years, HIV and AIDS has a profound impact on the social and economic development of the country as the age groups mostly affected are the economically active group, between the ages of 29 and 35 years (Department of Health, 2013). A study in the South African automotive manufacturing sector revealed that $33 \%$ of companies perceived HIV and AIDS to have a major impact on profits and indicated that investment decisions were influenced by HIV and AIDS related factors (Van Wyngaardt, 2010). However, the SABCOHA 2005 survey found that in comparison to medium and large companies, small companies (fewer than 100 employees) have reported less noticeable HIV and AIDS related impacts (Ellis, 2006; Ellis \& Terwin, 2005). It is also known that small and medium-sized enterprises (SMEs) face a number of structural constraints to implementing workplace programmes, including a lack of designated human resource personnel (Connelly \& Rosen, 2005; Hannon et al., 2012). The lack of resources is also hindering the proper assessment of needs and the monitoring and evaluation of interventions. Scepticism about the likely effectiveness of health promotion programmes could be linked to the anticipated investment costs required for workplace interventions in relation to the possible benefits (George \& Quinlan, 2009).

Current practice shows that large South African original equipment manufacturers (OEMs) like for example Ford, VW, GM and Mercedes-Benz have incorporated HIV and AIDS programmes into wellness programmes, also addressing other health conditions (Panter, 2009). This is supported by findings of large surveys, for example the global survey of health promotion, workplace wellness and productivity strategies (Buck Consultants, 2014), which have reported that in African workplaces, workplace safety, work-life issues and stress were, next to infectious diseases and HIV and AIDS, mentioned as the most important health issues driving the corporate wellness strategy. Several literature sources recommend extending the scope of workplace interventions beyond HIV related issues (Arend, 2008; Dickinson, 2008).

Furthermore, the inter-relatedness of various risky lifestyle factors linked to health conditions necessitate a comprehensive health promotion approach. For example, HIV infection is the strongest risk factor for tuberculosis (TB) and is responsible for South Africa's TB epidemic, further compounded by increasing drug resistance (Abdool Karim, Churchyard, Abdool Karim \& Lawn, 2009). People abusing alcohol and drugs are known to be at greater risk for HIV infection due to the increased likelihood for 
engaging in unprotected sex (Fisher, Bang \& Kapiga, 2007; Rehm, Shield, Joharchi \& Shuper, 2012). Problematic use of alcohol is high amongst employees in many South African industry sectors with alcohol use being a major risk factor for communicable and noncommunicable diseases, injuries and mental disorders (Parry, Patra \& Rehm, 2011; Rehm et al., 2010). Furthermore, alcohol abuse by employees can cause serious accidents and interfere with work efficiency and precision. Alcohol and drug abuse has been found to significantly impact employee work performance and absenteeism (Chakraborty \& Subramanya, 2013; Verster et al., 2010).

A statistically positive relationship is also found between stress and substance use, that is, alcohol and smoking (Azagba \& Sharaf, 2011, 2012a; Hassani et al., 2014). The use of both substances are known risk factors for various chronic diseases, such as asthma (Henneberger et al., 2015), cardiovascular disease and related conditions (Chandola et al., 2008). Stress on the other hand, is also associated with increased body mass index (Azagba \& Sharaf, 2012b), anxiety, depression, hostility and headaches (Stansfeld \& Candy, 2006), which are conditions linked to both absenteeism and presenteeism. Several studies confirm the relationship of musculoskeletal symptoms amongst workers and the physical, psychosocial and organisational environment in the workplace and consequently argue for a multifaceted approach by improving physical, psychosocial and organisational aspects of the working environment (Frederiksen, Karsten, Indahl \& Bendix, 2015; Widanarko, Legg, Devereux \& Stevenson, 2012, 2014).

Evidence exists for the health and well-being effects of WWPs linked to increased productivity and job satisfaction (Aldana, Merrill, Price, Hardy \& Hager, 2005; Blake, Zhou \& Batt, 2013; Torp, Grimsmo, Hagen, Duran \& Gudbergsson, 2013). The cost effectiveness of WWPs is particularly enhanced when both physical and psychosocial factors are addressed (Cancelliere, Cassidy, Ammendolia \& Côté, 2011). This could also be applicable to small businesses as there is evidence that by integrating wellness into their culture and operations, small companies can improve the health of the entire workforce population (Merrill et al., 2011).

The literature provides a vast range of arguments to support the implementation of holistic WWPs addressing the various health influencing factors impacting on employees and consequently the organisation. However, in reality, the availability of data to inform company management about the specific needs of their employees with regard to health issues might be limited (ILO, 2009; WHO, 2015). As little information is available on the views of companies in the South African automotive sector about health conditions impacting their production costs, ways in which these are monitored and managed as well as their views about current interventions, this study aims to explore these issues to better inform WWPs in this sector.

\section{Method \\ Research approach}

The study is an exploratory descriptive study using a quantitative research approach. A cross-sectional survey was conducted amongst companies in the automotive manufacturing sector in South Africa.

\section{Participants}

An updated, representative South African AIDC EC database with 527 companies was used as the sampling frame for the stratified random sampling of 258 companies across all nine provinces. The realised sample comprised 74 companies from a total of 167 companies who initially agreed to participate in the study. The survey questionnaire was directed at company representatives, such as human resource managers or general managers.

\section{Measuring instruments}

The survey questionnaire was designed to be selfadministered and to investigate the following aspects: company details (size, annual turnover, number of employees and skills level), questions with regard to the impact of health conditions on production costs, monitoring efforts and success in management of health conditions using a fivepoint Likert scale. Items pertaining to company responses to HIV and AIDS and general wellness were also included. A pilot study was conducted to assess the appropriateness of the questionnaire before data collection.

\section{Data collection}

The company representatives were contacted to negotiate study participation. The aims and objectives of the study, the voluntary nature of participation, confidentially and anonymity of data were discussed. The data collection process was clarified: instruments were either distributed via fax or email to be returned within a two-week period, with follow-up calls as a reminder. Whilst only 74 companies returned their questionnaires, they were well distributed across the provinces in relation to the database used as a sampling frame. Missing information was minimal and random.

\section{Data analysis}

Data processing and analysis were conducted using SPSS 19 (Statistical Package for the Social Sciences). Frequencies were calculated for all the items followed by descriptive and central tendency exploration. Recoding was done to improve the response categories for analysis; company size was coded as small (8-49 employees), medium (50-199 employees) and large (200+ employees). Company ownership was coded as multinational organisations (1) and national or local ownership (2).

Non-parametric tests were used as the data was not normally distributed. Kruskall-Wallis tests were conducted to assess the median scores of the different sized 
companies pertaining to: perceived impact of different health conditions on their production costs, the extent of their monitoring efforts and success in the management of the health conditions, beliefs about the likely success of WWPs and HAWPs to address their health challenges and views of health conditions that should be included in WWPs.

The Mann-Whitney $U$-tests were used to assess the difference between multinational and national organisations on the above measures. In addition these tests were also used to assess the difference between those who indicated having a WWP (Yes or No) pertaining to perceptions about the monitoring and perceived success in the management of health conditions. Cohen's (1988) criteria was used to assess the effect sizes $(0.1=$ small; $0.3=$ medium and $0.5=$ large).

Chi-square tests for independence were conducted to assess whether organisation size and ownership were associated with the following workplace wellness initiatives (Yes $=1$; No = 0): HAWP, HCT and antiretroviral treatment (ART) services and WWP. The phi coefficient effect size statistic was used for two-by-two tables (small effect $=0.01$, medium effect $=0.03$ and large effect $=0.05$ ) whilst Cramer's V was used for larger tables (small effect $=0.01$, medium effect $=$ 0.03 and large effect $=0.05$ ). In addition, Mann-Witney $U$-tests were also used to investigate the presence of different HIV and AIDS related initiatives, such as HAWP, HCT and ART services (Yes or No) pertaining to the perceived impact of HIV and AIDS on their production costs (not depicted in any table). Spearman's correlation analysis was done to assess the association between the perceived success of HAWPs and WWPs in addressing organisations' health challenges (not in table).

\section{Results \\ Company location and characteristics}

Most of the questionnaires were completed by company managers $(45 \% ; n=33)$, followed by human resources managers (38\%; $n=28)$ and administrative staff $(11 \%$; $n=7)$; only a few company CEOs $(5 \% ; n=4)$ completed the questionnaires (missing data for two companies). This designation varied depending on the size and the turnover of the company. Only $25 \%$ of companies were multinational whilst the rest were national organisations. More than 50\% of the participating companies reported an annual turnover of more than R50 million. With regard to the geographic location of the companies, the provincial distribution showed that the majority (51\%) of companies was from the Eastern Cape, followed by Gauteng (22\%), Kwazulu-Natal (18\%), Western Cape (8\%) and North West (1\%).

Most participating companies were medium to large companies (43.3\%) employing between 200 and 499 people fulltime, followed by micro to small companies (56.7\%) employing between 8 and 49 people. Unskilled employees accounted for 21\%, followed by semi-skilled (27.12\%), skilled (26.7\%) and highly skilled employees (25.10\%). The employees of most organisations, irrespective of size, seemed to be semi-skilled and skilled. Slightly more highly skilled employees were employed across all organisations than unskilled employees.

\section{Perceived impact of health influencing factors on production costs}

About half of the organisations perceived that most health factors have a small impact on their production costs. Overall, HIV and AIDS and smoking were considered by $34 \%$ and $36 \%$ of organisations respectively to have a moderate to large influence followed by alcohol use $(30 \%)$, stress $(29 \%)$, chronic back and neck ache $(25 \%)$, tuberculosis $(24 \%)$, hypertension $(21 \%)$, diabetes $(14 \%)$, hypercholesterolemia (7\%) and lastly obesity (6\%) (not in table).

The Kruskall-Wallis tests (depicted in Table 1), indicated that smaller companies generally perceived most health conditions to have a smaller impact on their production costs than medium to large organisations with the exception of TB and chronic back and neck ache, for which they reported a similar impact to medium-sized organisations. For HIV and AIDS, tuberculosis and alcohol use, medium-sized and large organisations indicated a similar impact on their production costs whilst smoking and hypercholesterolemia were seen more serious by larger organisations in comparison to the others.

With regard to the differences between multinational and national enterprises (not depicted in a table), the MannWitney $U$-test showed a significant difference in the perceived impact of HIV and AIDS by multinational ( $\mathrm{Md}=3, n=17$ ) and national $(\mathrm{Md}=2, n=54)$ enterprises $(U=306, z=-2.12$, $p=0.034)$. Multinational companies recorded a higher median score for the impact of HIV and AIDS than others. A medium effect was found $(r=0.25)$.

\section{Monitoring efforts of health influencing conditions on production costs}

With regard to the monitoring efforts of health conditions in organisations, the data shows that HIV and AIDS is best monitored (56\%), followed by alcohol use (52\%), tuberculosis (46\%) and then hypertension (36\%). The health conditions that are least monitored are obesity (48\%), hypercholesterolemia (41\%) and diabetes (37\%) (not in table). A statistically significant difference in the monitoring efforts of health conditions was noted in the Kruskall-Wallis tests between the different sized companies (Table 1). Diabetes, hypertension, HIV and AIDS and TB were generally well monitored by large organisations whilst HIV and AIDS also seems to be better monitored than the other conditions in small and medium-sized organisations. The Mann-Witney $U$-test did not show any significant differences with regard to the monitoring efforts 
TABLE 1: The impact, monitoring and successful management of health conditions by company size.

\begin{tabular}{|c|c|c|c|c|c|c|c|c|c|c|}
\hline \multirow[t]{2}{*}{ Health management } & \multirow[t]{2}{*}{ Health factors ${ }^{a}$} & \multirow[t]{2}{*}{$N$} & \multirow[t]{2}{*}{$X^{2}(d f=2)$} & \multirow[t]{2}{*}{$p$} & \multicolumn{6}{|c|}{ Median $^{b}$} \\
\hline & & & & & Small & $n$ & Medium & $n$ & Large & $n$ \\
\hline \multirow{7}{*}{$\begin{array}{l}\text { Perceived impact of health factors } \\
\text { on company's production costs }\end{array}$} & Diabetes & 72 & 15.95 & $<0.001$ & 1 & 21 & 2 & 19 & 2 & 32 \\
\hline & Smoking & 72 & 21.95 & $<0.001$ & 1 & 21 & 2 & 19 & 3 & 32 \\
\hline & Hypercholesterolemia & 72 & 26.53 & $<0.001$ & 1 & 21 & 2 & 19 & 3 & 32 \\
\hline & HIV and AIDS & 71 & 14.80 & 0.001 & 1 & 20 & 3 & 19 & 3 & 32 \\
\hline & Alcohol & 73 & 12.14 & 0.002 & 1 & 21 & 3 & 19 & 3 & 32 \\
\hline & Obesity & 71 & 9.31 & 0.009 & 1 & 20 & 2 & 19 & 2 & 32 \\
\hline & Back and neck ache & 72 & 8.68 & 0.013 & 2 & 21 & 2 & 19 & 3 & 32 \\
\hline \multirow{4}{*}{$\begin{array}{l}\text { Monitoring of health conditions } \\
\text { on production costs }\end{array}$} & Diabetes & 73 & 16.99 & $<0.001$ & 1 & 21 & 2 & 19 & 4 & 33 \\
\hline & Hypertension & 73 & 12.78 & 0.002 & 2 & 21 & 2 & 19 & 4 & 33 \\
\hline & HIV and AIDS & 72 & 10.64 & 0.005 & 2.5 & 20 & 4 & 19 & 4 & 33 \\
\hline & Tuberculosis & 72 & 8.525 & 0.014 & 2 & 21 & 3 & 19 & 4 & 32 \\
\hline \multirow{6}{*}{$\begin{array}{l}\text { Success in managing the impact } \\
\text { of health conditions on production } \\
\text { costs }\end{array}$} & Hypercholesterolemia & 71 & 17.38 & $<0.001$ & 1 & 20 & 1 & 18 & 3 & 33 \\
\hline & Diabetes and blood sugar & 71 & 28.40 & $<0.001$ & 3 & 20 & 3 & 18 & 4 & 33 \\
\hline & HIV and AIDS & 72 & 13.90 & 0.001 & 1.5 & 20 & 2 & 19 & 4 & 33 \\
\hline & Tuberculosis & 71 & 10.93 & 0.004 & 1.5 & 20 & 2 & 18 & 4 & 33 \\
\hline & Back and neck ache & 72 & 6.93 & 0.030 & 1 & 20 & 1 & 19 & 3 & 33 \\
\hline & Smoking & 71 & 6.08 & 0.004 & 1 & 20 & 2.5 & 18 & 3 & 33 \\
\hline \multirow{2}{*}{$\begin{array}{l}\text { Perceived success of different } \\
\text { workplace programmes to manage } \\
\text { health conditions }\end{array}$} & WWP & 70 & 11.77 & 0.003 & 2 & 21 & 4 & 18 & 4 & 31 \\
\hline & HIV and AIDS Programmes & 69 & 13.42 & 0.001 & 2 & 21 & 4 & 16 & 4 & 32 \\
\hline
\end{tabular}

a, Significant results of Kruskall-Wallis tests $(p \leq 0.05) ;{ }^{\text {}}$, Range $1-5$.

of health conditions between national and multinational organisations (not shown in a table).

\section{Success in managing the impact of health factors on production costs}

HIV and AIDS appears to be the most successfully managed condition as $53 \%$ of companies reported moderate to high levels of success, followed by alcohol and TB (46\% and 39\% respectively) and then hypertension and smoking by $30 \%$ of companies. Marginal success was reported by most in the management of smoking (37\%), whilst $30 \%$ of companies indicated moderate to high levels of success. However, few organisations considered themselves to be successful in addressing obesity and hypercholesterolemia ( $8 \%$ and $18 \%$ respectively) amongst their employees (frequencies are not depicted in a table).

The Kruskall-Wallis test results (Table 1) suggest that large organisations are generally more likely to successfully address the impact of various health conditions on their production costs than medium and small enterprises. In particular, great success was reported with hypertension, hypercholesterolemia and chronic back and neck ache followed by HIV and AIDS and TB. The management of smoking and diabetes seemed however to be less effective and the difference from other sized organisations was less enhanced.

The Mann-Witney $U$-test revealed a significant difference in the perceived success in the management of tuberculosis by multinational $(\mathrm{Md}=4, n=18)$ and national $(\mathrm{Md}=3, n=53)$ organisations $(U=325.5, z=-2.06, p=0.04)$. Multinational organisations had a higher mean score for the management of tuberculosis. The effect $(r=0.244)$ can be considered to be a small to medium one (not depicted in a table).

\section{Workplace health promotion initiatives}

More than half of the companies (52.1\%) reported having workplace wellness programmes irrespective of company size or ownership. Of the companies surveyed, 70.4\% indicated having an HIV and AIDS education programme, 57.5\% offered HCT services, whilst fewer organisations (21.1\%) provided ART services. According to the Chisquare results, organisations that reported having a wellness programme were more likely to indicate also having an HIV and AIDS education programme $\left(X^{2}=5.035\right.$, $d f 1, p=0.025$, phi $=0.30)$ and HCT services $\left(X^{2}=8.208\right.$, $d f 1, p=0.004$, phi $=0.37)$. Larger organisations were also significantly more likely to have HIV and AIDS education programmes $\left(X^{2}=7.003, d f 2, p=0.03\right.$, Cramer's $\left.V=0.432\right)$ and HCT services $\left(X^{2}=13.229, d f 2, p=0.001\right.$; Cramer's $V=0.432)$ than other medium and smaller organisations. No differences were detected for ART services amongst the different sized companies. In addition, the Mann-Witney $U$-test revealed that the mean score for the perceived impact of HIV and AIDS differed between organisations that indicated having an HIV and AIDS education programme $(\mathrm{Md}=3, n=49)$ and those that did not $(\mathrm{Md}=2, n=20$; $U=314, z=-2.392, p=0.017$, medium effect size: $r=0.288)$. Those that had a HAWP obtained a higher mean score on perceived HIV and AIDS impact. The above results are not depicted in a table.

When investigating the experiences of companies with and without a WWP, it was clear that those that indicated having a WWP seemed better able to monitor the health 
TABLE 2: Monitoring and management of health conditions by presence of workplace wellness programmes.

\begin{tabular}{|c|c|c|c|c|c|c|c|c|c|c|}
\hline \multirow[t]{2}{*}{ Health management } & \multirow[t]{2}{*}{ Health conditions $\mathrm{s}^{\mathrm{a}}$} & \multirow[t]{2}{*}{$N$} & \multirow[t]{2}{*}{$\boldsymbol{U}$} & \multirow[t]{2}{*}{$z$} & \multirow[t]{2}{*}{$\bar{p}$} & \multicolumn{4}{|c|}{ Median $^{b}$} & \multirow[t]{2}{*}{$r^{c}$} \\
\hline & & & & & & Yes WWPS & $n$ & No WWP & $n$ & \\
\hline \multirow{6}{*}{$\begin{array}{l}\text { Monitoring of health conditions in } \\
\text { presence or absence of WWP }\end{array}$} & Diabetes & 71 & 407.0 & -2.638 & 0.008 & 3 & 37 & 2 & 34 & 0.306 \\
\hline & Hypertension & 71 & 409.5 & -2.586 & 0.010 & 3 & 37 & 2 & 34 & 0.300 \\
\hline & Back and neck ache & 71 & 415.0 & -2.534 & 0.011 & 3 & 37 & 2 & 34 & 0.294 \\
\hline & Obesity & 71 & 426.5 & -2.483 & 0.013 & 2 & 37 & 1 & 34 & 0.288 \\
\hline & Hypercholesterolemia & 71 & 448.5 & -2.170 & 0.030 & 2 & 37 & 1 & 34 & 0.252 \\
\hline & Stress & 71 & 450.0 & -2.116 & 0.340 & 2 & 37 & 1 & 34 & 0.246 \\
\hline \multirow{7}{*}{$\begin{array}{l}\text { Perceived success in the management of } \\
\text { health conditions in presence or absence } \\
\text { of WWP }\end{array}$} & Obesity & 68 & 369.0 & -2.925 & 0.003 & 2 & 37 & 1 & 32 & 0.354 \\
\hline & Stress & 70 & 366.0 & -3.013 & 0.003 & 3 & 37 & 1 & 33 & 0.360 \\
\hline & Smoking & 69 & 372.0 & -2.745 & 0.006 & 3 & 37 & 1 & 32 & 0.330 \\
\hline & Hypercholesterolemia & 69 & 345.0 & -3.151 & 0.002 & 3 & 37 & 1 & 32 & 0.378 \\
\hline & Hypertension & 69 & 343.5 & -3.144 & 0.002 & 3 & 37 & 1 & 32 & 0.378 \\
\hline & Diabetes & 69 & 314.5 & -3.522 & $<0.001$ & 3 & 37 & 1 & 32 & 0.424 \\
\hline & HIV and AIDS & 70 & 394.5 & -2.614 & 0.009 & 4 & 37 & 3 & 33 & 0.312 \\
\hline
\end{tabular}

WWP, workplace wellness programme.

a, Significant Mann-Whitney $U$-test results $(p \leq 0.05)$; ${ }^{\text {, }}$ Range $1-5 ;$ ' , Cohen's criteria: $0.1=$ small effect; $0.3=$ medium effect; $0.5=$ large effect.

TABLE 3: Health conditions to address in a workplace wellness programmes.

\begin{tabular}{|c|c|c|c|c|c|c|c|c|c|}
\hline \multirow[t]{2}{*}{ Health factor ${ }^{\mathrm{a}}$} & \multirow[t]{2}{*}{$N$} & \multirow[t]{2}{*}{$X^{2}(d f=2)$} & \multirow[t]{2}{*}{$p$} & \multicolumn{6}{|c|}{ Median $^{b}$} \\
\hline & & & & Small & $n$ & Medium & $n$ & Large & $n$ \\
\hline Diabetes & 71 & 17.19 & $<0.001$ & 2 & 20 & 3 & 19 & 4 & 32 \\
\hline Obesity & 71 & 16.72 & $<0.001$ & 2 & 20 & 3 & 19 & 3 & 32 \\
\hline Hypertension & 71 & 15.96 & $<0.001$ & 3 & 20 & 4 & 19 & 4 & 32 \\
\hline Stress & 71 & 13.58 & 0.001 & 3 & 20 & 4 & 19 & 4 & 32 \\
\hline High cholesterol & 69 & 12.31 & 0.002 & 2 & 19 & 3 & 19 & 4 & 31 \\
\hline Back or neck ache & 71 & 8.67 & 0.013 & 3 & 20 & 3 & 19 & 4 & 33 \\
\hline Tuberculosis & 72 & 7.66 & 0.022 & 3.5 & 20 & 5 & 18 & 4 & 32 \\
\hline HIV and AIDS & 72 & 7.41 & 0.025 & 3.5 & 20 & 5 & 19 & 5 & 33 \\
\hline Smoking & 71 & 6.68 & 0.035 & 3 & 20 & 4 & 19 & 4 & 32 \\
\hline
\end{tabular}

a, Significant results of Kruskall-Wallis tests $(p \leq 0.05)$; ${ }^{\text {, Range } 1-5 .}$

conditions and appeared to be more successful than those without a WWP in managing the impact of the various health conditions on their production costs. The results of the Mann-Whitney $U$-tests (see Table 2) suggest that organisations with a wellness programme were significantly better able to monitor diabetes, hypertension, chronic back and neck ache, obesity, hypercholesterolemia, HIV and AIDS, as well as stress. Similarly, companies with a wellness programme seemed also more successful in managing the impact of obesity, stress, smoking, hypercholesterolemia, hypertension, diabetes chronic back and neck ache as well as HIV and AIDS on their companies' production costs than the others. This was however more enhanced for stress, smoking, hypercholesterolemia, hypertension, diabetes and chronic back and neck ache than for HIV and AIDS.

The Kruskall-Wallis tests showed a significant difference in the mean scores for the small versus medium and large organisations with regard to the perceived success of WWPs $\left(X^{2}=11.77, d f 2, p=0.003\right)$, and HAWPs $\left(X^{2}=13.42, d f 2\right.$, $p=0.001$ ) in addressing their health challenges (Table 1 ). Smaller organisations were not convinced about the likely success of both these programmes whilst medium and large organisations were more supportive $(\mathrm{Md}=2$ versus $\mathrm{Md}=4$ respectively for both WWP and HAWP on a range of 1-5).
Furthermore, a strong positive correlation $(r=0.796)$ was found between perceived success of a comprehensive WWP and HAWP in addressing company health challenges (not depicted in a table).

The above study findings suggest not only the importance of the impact of HIV and AIDS on organisation's production costs, but also that other health influencing factors are of concern. Companies that reacted by implementing WWP instead of HAWP were not only more successful in monitoring the impact but also seemed to be more successful in managing most health conditions.

\section{Health conditions perceived to be an important focus for workplace wellness programmes}

The majority of companies believed that a WWP should pay considerable attention to HIV and AIDS (57\%), followed by tuberculosis (38\%), alcohol use (28\%) and stress and smoking (both 25\%). In accordance to the outcomes of the KruskallWallis tests as depicted in Table 3, larger organisations seemed to believe that most health factors should receive attention in WWP in comparison to smaller organisations. No significant differences were detected in the MannWhitney $U$-tests for multinational and local organisations in this regard (not in table). 


\section{Discussion}

The organisations that responded to the survey reflect the broad range in the automotive sector spanning from small and medium to large organisations with turnover rates ranging from less than $\mathrm{R} 5$ million to more than R50 million. Despite the relatively small sample, when compared to the existing AIDC EC database, the sample does reflect the larger population with regard to size and multinational and national ownership of the organisations in the automotive sector. Representation of different sized organisations is particularly important, as micro and small organisations have not responded adequately to the challenges posed by HIV and AIDS due to limited financial resources and expertise in this regard (Ellis \& Terwin, 2005; Vass \& Phakathi, 2006).

\section{Perceived impact of health conditions on production costs}

The health conditions that are perceived by the organisations to have a moderate to large impact on their production costs are HIV and AIDS, smoking, alcohol use, stress, chronic back and neck ache and tuberculosis. Small organisations generally perceive most conditions to have a smaller impact than larger organisations. The likely interactive relationships between the concerned health conditions are striking. Alcohol use is known to increase the risk for HIV infection due to the likelihood of unprotected sexual activities (Fisher et al., 2007; Rehm et al., 2012). Closely linked to HIV infection is TB; the comorbidity of tuberculosis with HIV is well researched in South Africa (Abdool Karim et al., 2009; Harries et al., 2010; UNAIDS, 2011) and often used as an indirect indicator of HIV prevalence. Stress levels on the other hand have been reported to have a positive and statistically significant association with alcohol consumption and smoking intensity (Azagba \& Sharaf, 2011). These health influencing factors are also known risk factors for various chronic diseases (Azagba \& Sharaf, 2011; Lucini, Solaro, Lesma, Gillet \& Pagani, 2011). Chronic stress has been linked to a wide range of adverse health outcomes such as cardiovascular disease and hypertension (Azagba \& Sharaf, 2011; Babu et al., 2014; Chandola et al., 2008; Lucini et al., 2011), as well as back and neck pain (Widanarko et al., 2012). It is thus not surprising that all these health conditions were raised as posing some concern for the organisations surveyed.

The consensus that HIV and AIDS impacts company production costs supports the negative influence of a generalised HIV and AIDS epidemic on the South African economy (Thurlow, Gow \& George, 2009; Van Zyl \& Lubisi, 2009). It also concurs with the study of Van Zyl and Lubisi (2009) in which HIV and AIDS was found to negatively impact company productivity levels, labour, profit levels, prices and sales. Concerns about alcohol use should be noted as it not is only linked to increased risk for HIV infection, but also has detrimental consequences for organisations (Kirkham et al., 2015; McFarlin \& Fals-Stewart, 2002; Osilla et al., 2010). Alcohol use impacts negatively on levels of absenteeism and productivity, whilst intoxication poses serious safety concerns (Atkinson, 2001, as cited in Elliott \& Shelley, 2005). The legal framework for occupational health and safety places a large responsibility on organisations to ensure a safe workplace and necessitates the close monitoring and management of alcohol use in the workplace. Organisations viewed alcohol use and smoking as having an impact on their production costs, possibly linked to a loss of productivity due to alcohol-related absenteeism and multiple smoking breaks amongst smokers (SABCOHA, 2012; Sarna et al., 2009). Substance use might also be more noticeable than other health influencing conditions.

\section{Monitoring and managing of health conditions in the organisation}

The perceived impact of health issues on production costs seemed to be linked to the monitoring efforts of health conditions. HIV and AIDS, alcohol use, TB and hypertension were reported to be best monitored by medium to large organisations. Organisations were also more likely to perceive having some success in the management of these conditions. Organisations who perceived HIV and AIDS to have a negative impact were also more likely to have a HAWP, offer HCT and ART services and were thus able to manage HIV and AIDS. The importance of the workplace as a setting for HCT has been highlighted in research (Corbett et al., 2006, 2007). Despite the fact that the greater majority of organisations indicated having a HAWP and showing some commitment to the fight against HIV and AIDS, it was more so for larger than smaller organisations, a finding that is also supported by previous studies (Elliott \& Shelley, 2005; Vass \& Phakathi, 2006). However, the management success of various health influencing factors was more likely in organisations with WWPs. Similarly, the SABCOHA survey (Ellis \& Terwin, 2005) reported that the sectors more profoundly affected by HIV and AIDS tend to have the most mature programmes and many have integrated HAWP into broader WPPs. The results of this study support these findings as companies that had a WWP were significantly better able to monitor HIV and AIDS and appeared to be more successful than those without a WWP in managing the impact of HIV and AIDS on their production costs.

The inability of small organisations to monitor and successfully manage particularly HIV and AIDS, TB and hypertension is likely due to the absence of WWPs. The absence of WWP is possibly a result of limited human and financial resources hampering the implementation of effective interventions as supported in other studies (Connelly \& Rosen, 2006; Ellis \& Terwin, 2005; Vass \& Phakathi, 2006).

\section{Workplace health promotion initiatives}

The implementation of WWPs in 52\% of the organisations surveyed, irrespective of organisation size, is encouraging and augurs well for enhancing wellness in the workplace. International research indicates that larger organisations are generally more likely to implement health promotion 
programmes (holistic WWPs) than smaller organisations (Harris, Huang, Hannon \& Williams, 2011; Linnan et al., 2008). Similarly to the SABCOHA findings (Ellis \& Terwin, 2005), the organisations with a WWP were more likely to perceive HIV and AIDS and other health conditions as having an impact on their production costs, a perception most likely to have contributed to the implementation of a WWP, thereby contributing to greater levels of success in the management of these health influencing factors. These organisations were also more likely to have a HAWP and offer HCT and access to ART. Rosen, Feeley, Connelly and Simon (2007) report that for large organisations, the provision of ART to employees was seen as a good investment whilst small and even medium-sized companies had restricted human and financial capacity to respond in this regard. Efforts to reach out to SMEs in the automotive sector to assist them in capacity building and WWP implementation have been initiated by for example SABCOHA (2012), AIDC EC and development agencies like Deutsche Gesellschaft für Internationale Zusammenarbeit (GIZ).

The attention paid to TB by most companies is encouraging although small companies do not seem to have much success in the management of TB. The capacity in the workplace to monitor the quality of care to employees with TB is of critical importance in efforts to support TB treatment completion. Evidence exists for the cost effectiveness of public-private workplace (PWP) provision of TB treatment in South Africa to reduce costs for the patient, workplace and government (Sinanovic \& Kumaranayake, 2006a, 2006b, 2010). As larger organisations were more likely to monitor and report success in the management of $\mathrm{TB}$, successful workplace support for directly observed treatment (DOT), the internationally supported control strategy for $\mathrm{TB}$, would be more likely in organisations with well supported, resourced and comprehensive WWPs.

Most organisations believed that WWPs, and to a lesser extent that HAWPs, would be successful in addressing their health challenges. The support for a more comprehensive WWP is understandable as various other health factors apart from HIV and AIDS were highlighted as impacting negatively on organisations' production costs and therefore as important to address in WWPs, in particular tuberculosis, substance use and stress. These lifestyle factors, as mentioned earlier, have been found to impact negatively on the health and wellbeing of workforces and thus on organisation effectiveness. Human resources can be considered an organisation's most important resource; employee well-being is therefore a key factor to long-term organisational effectiveness. Research studies have shown positive relationships between employee health and well-being and productivity levels (Bloom, Canning \& Sevilla, 2005; Cancelliere et al., 2011; Kuoppala, Lamminpää \& Husman, 2008).

However, small organisations were less likely to be convinced about the likely success of both HAWPs and WWPs in addressing their health challenges. This finding helps to explain the reluctance of small companies in the
South African automotive sector to implement HAWPs and possibly also WWPs. This scepticism about the likely effectiveness of health promotion programmes could be linked to the anticipated investment costs required for workplace interventions in relation to the possible benefits as highlighted by George and Quinlan (2009). Furthermore, the limited available human resources in small organisations may account for this view. Hannon et al. (2012) recently found that a lack of capacity was a key barrier to the implementation of health promotion programmes in low-wage industries in the US. Apart from a few specific case studies, little research evidence exists for the effectiveness of HAWP in the South African context, whilst WWP in South Africa is still in its infancy. Organisations should be made aware of the importance of monitoring and evaluating HAWPs and WWPs and to share their findings. International evidence exists for the health-enhancing effects and cost effectiveness of workplace wellness programmes (Aldana et al., 2005; Allen, Lewis \& Tagliaferro, 2012). However, best evidence suggests that WWP should address both psychosocial and physical factors (Cancelliere et al., 2011; Kuoppala et al., 2008). Successful WWPs thus imply not merely a disease focus, but require a change in an organisation's 'health culture' to ensure a supportive environment for health and well-being, fully integrated into the mission and vision of the organisation (Blake \& Lloyd, 2008).

The results of this study contribute to a better understanding of the perceived salient health influencing factors that impact automotive organisations' production costs. But more importantly, the results support the known interrelationships between the identified health concerns and calls for more holistic wellness programmes. In addition, efforts to facilitate a participatory process amongst relevant stakeholders (e.g. employees, family members and unions) to better understand the health-related needs of the workforce will contribute further to a relevant and nuanced health promotion response.

As companies' competitiveness and growth seem to hinge on the effectiveness of health promotion interventions, the implementation of comprehensive WWPs is therefore a convincing organisational strategy to not only address the concerned health conditions and successfully address the HIV and AIDS pandemic, but also to foster general workplace well-being.

\section{Limitations}

Whilst the response rate of $29 \%$ is generally low, despite attempts to motivate a higher return rate, the response rate is similar to other electronic mail surveys, ranging between $20 \%$ and 24\% (Kaplowitz, Hadlock \& Levine, 2004). The feedback received indicated that the timing of the survey, just before the yearly Christmas recess with increased production demands, impacted on the response rate. The study findings are limited to perceptions of managers. These perceptions are not necessarily based on objective company policies and therefore some level of bias is possible. 


\section{Recommendations}

Based on the results of this study, the following recommendations are proposed.

\section{Partnership approach to support workplace wellness programmes}

A greater awareness of existing networks should be facilitated using organisations such as SABCOHA, other nongovernmental organisations and the public sector to assist in companies' wellness intervention needs. The facilitation of partnerships with other institutions to assist in HIV and AIDS service provision, including the treatment of other sexually transmitted infections, opportunistic infections (especially TB) and counselling support will be helpful to address organisations' concerns regarding HIV and AIDS. However, the integration of HIV and AIDS interventions within WWPs seems appropriate as HIV and AIDS were not considered by all organisations to have the most severe impact on production costs. Smaller companies in particular need support in the development of tailored and costeffective interventions, based on needs and risk assessments and directed first at addressing their more immediate health concerns, so that they may reap the benefits of well-designed interventions. Also, more emphasis needs to be placed on monitoring and evaluation of interventions. This process could initiate a necessary attitude change in becoming less sceptical of the likely success of WWP.

\section{Comprehensive workplace wellness programmes}

A comprehensive, workplace health promotion approach would provide a cost-effective and sustainable way to address the multitude of health influencing factors apart from HIV and AIDS impacting on both the individual employees and the business alike. Support seems to exist for addressing various health conditions within WWPs and this reiterates the need to strengthen and extend existing efforts to broaden its predominant disease focus. In particular, occupational stress as a risk factor for substance use, cardiovascular diseases and safety should be addressed at both an individual and organisational level.

The existing occupational health and safety initiatives in the workplace could provide opportunities to extend health and well-being programmes. Greater effort is thus required to advocate for a comprehensive approach to health and well-being in the workplace that calls for supportive leadership, relevant policies and systems in the workplace as well as the fostering of an organisational culture to ensure that organisations become supportive environments for health and well-being grounded in ethical principles and values.

In addition, organisations will benefit from a deeper understanding of the views of WHO and ILO pertaining to health promotion's role in the transformation of organisations, as this could form an important foundation for developments in organisational change. The likely direct and indirect benefits from a holistic approach will not only improve individual employee health and well-being, but is also likely to create a workforce that feels valued and is committed and engaged.

\section{Conclusion}

The results of this study enhanced understandings of the perceived salient health influencing factors that impact the production costs of companies in the South African automotive sector. Apart from HIV and AIDS, substance use such as smoking and alcohol use, stress, chronic back and neck ache and tuberculosis, are deemed to pose challenges to the organisations. Importantly, the results point to the known inter-relationships between the identified health concerns and calls for more holistic wellness programmes. Companies' competitiveness and growth seem to hinge on the effectiveness of health promotion interventions; the implementation of comprehensive workplace wellness programmes is therefore a convincing organisational strategy to not only address the concerned health conditions and the HIV and AIDS pandemic, but also to foster general workplace well-being.

The study findings therefore call for the careful development and implementation of theoretically sound and appropriate workplace wellness interventions with cognisance of the holistic health-promoting workplace framework as suggested by the WHO (2015). Furthermore, careful monitoring and proper evaluation should be considered as an integral part of a responsible intervention approach. This will enable the development of scientifically based best evidence, necessary for the fostering of health and well-being in the South African workplace.

\section{Acknowledgements}

This work was conducted in 2010-2012 during a project run by the Automotive Industry Development Centre Eastern Cape (AIDC EC) and the Deutsche Gesellschaft fur Internationale Zusammenarbeit (GIZ), a technical development agency owned by the German government. Many thanks to the AIDC EC and GIZ. Many thanks also to the participating companies for permission to publish these findings.

\section{Competing interests}

The authors declare that they have no financial or personal relationships that may have inappropriately influenced them in writing this article.

\section{Authors' contributions}

A.M.-W. (University of KwaZulu-Natal) was the project leader. M.W. (AIDC EC and GIZ at the time of the study, Human Science Research Council at the time of completion of the work) and F.B.-W. (AIDC EC and GIZ at the time of the study, Nelson Mandela Metropolitan University at the time of completion of the work) were responsible for study design and data collection. Data analysis and calculations 
were performed by A.M.-W., who also wrote the manuscript, supported by F.B.-W. and M.W.

\section{References}

Abdool Karim, S.S., Churchyard, G.J., Abdool Karim, Q., \& Lawn, S.D. (2009). HIV infection and tuberculosis in South Africa: An urgent need to escalate the public health response. Lancet, 374(9693), 921-933. PMID: 19709731, http://dx.doi. org/10.1016/S0140-6736(09)60916-8

Aldana, S.G., Merrill, R.M., Price, K., Hardy, A., \& Hager, R. (2005). Financial impact of a comprehensive multisite workplace health promotion program. Preventive Medicine, 40(2), 131-137. PMID: 15533521, http://dx.doi.org/10.1016/j. ypmed.2004.05.008

Allen, J.C., Lewis, J.B., \& Tagliaferro, A.R. (2012). Cost-effectiveness of health risk reduction after lifestyle education in the small workplace. Preventing Chronic Disease, 9, E96. PMID: 22575081, http://dx.doi.org/10.5888/pcd9.110169

Arend, E.D. (2008). Wellness programme and health policy development at a large faith-based organisation in Khayelitsha, South Africa. African Journal of AIDS Research, 7(3), 259-270. PMID: 25875454, http://dx.doi.org/10.2989/ AJAR.2008.7.3.3.650

Azagba, S., \& Sharaf, M.F. (2011). The effect of job stress on smoking and alcohol consumption. Health Economics Review, 1(1), 1-14. PMID: 22827918, http:// dx.doi.org/10.1186/2191-1991-1-15

Azagba, S., \& Sharaf, M.F. (2012a). The association between workplace smoking bans and self-perceived, work-related stress among smoking workers. BMC Public
Health, 12(1), 1-8. PMID: 22329920, http://dx.doi.org/10.1186/1471-2458-12Health

Azagba, S., \& Sharaf, M.F. (2012b). The relationship between job stress and body mass index using longitudinal data from Canada. International Journal of Public Health, 57(5), 807-815. PMID: 22371003, http://dx.doi.org/10.1007/s00038-012-0348-y

Babu, G.R., Jotheeswaran, A.T., Mahapatra, T., Mahapatra, S., Kumar, A., Detels, R. et al. (2014). Is hypertension associated with job strain? A meta-analysis of observational studies. Occupational and Environmental Medicine, 71(3), 220-227. PMID: 24142979, http://dx.doi.org/10.1136/oemed-2013-101396

Blake, H., \& Lloyd, S. (2008). Influencing organisational change in the NHS: Lessons learned from workplace wellness initiatives in practice. Quality in Primary Care, 16(6), 449-455. PMID: 19094421

Blake, H., Zhou, D., \& Batt, M.E. (2013). Five-year workplace wellness intervention in the NHS. Perspectives in Public Health, 133(5), 262-271. PMID: 23771680, http:// dx.doi.org/10.1177/1757913913489611

Bloom, D.E., Canning, D., \& Sevilla, J. (2005). Health and economic growth: Reconciling the micro and macro evidence. Center on Democracy, Development and the Rule of Law Working Papers. Retrieved May 08, 2015, from http://www.anderson.ucla. edu/faculty_pages/romain.wacziarg/demogworkshop/Bloom and Canning.pdf

Buck Consultants. (2014). Working well: A global survey of health promotion, workplace wellness and productivity strategies. Retrieved May 08, 2015, from https://www.bucksurveys.com/bucksurveys/Surveys/GlobalWellness/tabid/72/ Default.aspx

Burton, J. (2010). WHO healthy workplace framework and model: Background and supporting literature and practices. Retrieved May 8, 2015, from http://apps.who. int//iris/handle/10665/113144

Cancelliere, C., Cassidy, J.D., Ammendolia, C., \& Côté, P. (2011). Are workplace health promotion programs effective at improving presenteeism in workers? A systematic promotion programs effective at improving presenteeism in workers? A systematic
review and best evidence synthesis of the literature. BMC Public Health, 11, 1-11. PMID: 21615940, http://dx.doi.org/10.1186/1471-2458-11-395

Chakraborty, S., \& Subramanya, A.H.C. (2013). Socio-demographic and clinical predictors of absenteeism - A cross-sectional study of urban industrial employees. Industrial Psychiatry Journal, 22(1), 17-21. PMID: 24459368, http://dx.doi. Industrial Psychiatry Journal, 221
org/10.4103/0972-6748.123589

Chandola, T., Britton, A., Brunner, E., Hemingway, H., Malik, M., Kumari, M. et al. (2008). Work stress and coronary heart disease: What are the mechanisms? European Heart Journal, 29(5), 640-648. PMID: 18216031, http://dx.doi. European Heart Journal, 29(5),
org/10.1093/eurheartj/ehm584

Cohen, J. (1988). Statistical power analysis for the behavioral sciences. (2nd edn.). Hillsdale, NJ: Lawrence Erlbaum. Retrieved n.d., from http://books.google.com/ books?id=TION2IRAO9oC

Connelly, P., \& Rosen, S. (2005). Will small and medium enterprises provide HIV/AIDS services to employees? An analysis of market demand. The South African Journal of Economics, 73(s1), 613-626.

Connelly, P., \& Rosen, S. (2006). Treatment of HIV/AIDS at South Africa's largest employers: Myth and reality. South African Medical Journal, 96(2), 128-133. PMID: 16532081

Corbett, E.L., Dauya, E., Matambo, R., Cheung, Y.B., Makamure, B., Bassett, M.T. et al. (2006). Uptake of workplace HIV counselling and testing: A cluster-randomised trial in Zimbabwe. PLoS Medicine, 3(7), e238. PMID: 16796402, http://dx.doi org/10.1371/journal.pmed.0030238

Corbett, E.L., Makamure, B., Cheung, Y.B., Dauya, E., Matambo, R., Bandason, T. et al. (2007). HIV incidence during a cluster-randomized trial of two strategies providing voluntary counselling and testing at the workplace, Zimbabwe. AIDS, 21(4), 483-489. PMID: 17301567

Department of Health. (2013). The 2012 National Antenatal Sentinel HIV \& Herpes Simplex Type-2 Prevalence Survey in South Africa. Retrieved May 08, 2015, from http://www.health-e.org.za/wp-content/uploads/2014/05/ASHIVHerp_ Report2014_22May2014.pdf
Department of Labour. (2000). HIV\&AIDS technical assistance guidelines. Retrieved July 30, 2015, from http://www.labour.gov.za/DOL/documents/usefuldocuments/employment-equity/hivaids-technical-assistance-guidelines

Department of Labour. (2012). Employment Equity Act, 1998 (ACT NO. 55 OF 1998): Code of good practice on HIV and AIDS and the world of work (2012). Retrieved May 08, 2015, from http://www.labour.gov.za/DOL/downloads/legislation/acts/ employment-equity/hivaidstechnicalguide.pdf

Dickinson, D. (2008). Traditional healers, HIV/AIDS and company programmes in South Africa. African Journal of AIDS Research, 7(3), 281-291. PMID: 25875456, http:// dx.doi.org/10.2989/AJAR.2008.7.3.5.652

Discovery. (2014). Healthy Company Index 2014. Retrieved May 08, 2015, from http:// healthycompanyindex.co.za/uploads/downloads/healthy-company-index-2014overall-report.pdf

Dornan, A., \& Jane-Llopis, E. (2010). The wellness imperative: Creating more effective organisations. Geneva: World Economic Forum. Retrieved n.d., from http://www3.weforum.org/docs/WEF_HE_Wellness/mperativeCreatingMore EffectiveOrganizations Report_2010.pdf

Elliott, K., \& Shelley, K. (2005). Impact of employee assistance programs on substance abusers and workplace safety. Journal of Employment Counseling, 42(3), 125-132. http://dx.doi.org/10.1002/j.2161-1920.2005.tb00906.x

Ellis, L.L. (2006). The economic impact of HIV/AIDS on small, medium and large entreprises. The South African Journal of Economics, 74(4), 682-701. http:// dx.doi.org/10.1111/j.1813-6982.2006.00093.x

Ellis, L.L., \& Terwin, J.E. (2005). The impact of HIV/AIDS on selected business sectors in South Africa, 2005. Retrieved May 08, 2015, from https://scholar.sun.ac.za/ handle/10019.1/40176

Fisher, J.C., Bang, H., \& Kapiga, S.H. (2007). The association between HIV infection and alcohol use: A systematic review and meta-analysis of African studies. Sexually Transmitted Diseases, 34(11), 856-863. PMID: 18049422

Frederiksen, P., Karsten, M.M.V., Indahl, A., \& Bendix, T. (2015). What challenges manual workers' ability to cope with back pain at work, and what influences their decision to call in sick? Journal of Occupation Rehabilitation. PMID: 25808992, $\mathrm{http}: / / \mathrm{dx}$.doi.org/10.1007/s10926-015-9578-1

George, G., \& Quinlan, T. (2009). 'Health management' in the private sector in the context of HIV/AIDS: Progress and challenges faced by company programmes in South Africa. Sustainable Development, 17(1), 19-29. http://dx.doi.org/10.1002/ sd.366

Hannon, P.A., Garson, G., Harris, J.R., Hammerback, K., Sopher, C.J., \& Clegg-Thorp, C. (2012). Workplace health promotion implementation, readiness, and capacity among midsize employers in low-wage industries: A national survey. Journal of Occupational and Environmental Medicine, 54(11), 1337-1343. PMID: 23090160 $\mathrm{http}: / / \mathrm{dx}$.doi.org/10.1097/JOM.0b013e3182717cf2

Harries, A.D., Zachariah, R., Corbett, E.L., Lawn, S.D., Santos-Filho, E.T., Chimzizi, R. et al. (2010). The HIV-associated tuberculosis epidemic - When will we act? Lancet, 375(9729), 1906-1919. PMID: 20488516, http://dx.doi.org/10.1016/S01406736(10)60409-6

Harris, J.R., Huang, Y., Hannon, P.A., \& Williams, B. (2011). Low-socioeconomic status workers: Their health risks and how to reach them. Journal of Occupational and Environmental Medicine, 53(2), 132-138. PMID: 21270663, http://dx.doi org/10.1097/JOM.0b013e3182045f2c

Hassani, S., Yazdanparast, T., Seyedmehdi, S.M., Ghaffari, M., Attarchi, M., \& Bahadori, B. (2014). Relationship of occupational and non-occupational stress with smoking in automotive industry workers. Tanaffos, 13(2), 35-42.

Henneberger, P.K., Liang, X., Lillienberg, L., Dahlman-Höglund, A., Torén, K., \& Andersson, E. (2015). Occupational exposures associated with severe exacerbation of asthma. International Journal of Tuberculosis and Lung Disease, 19(2), 244250. PMID: 25574926, http://dx.doi.org/10.5588/ijtld.14.0132

International Labour Organisation (ILO). (2009, June 15). Workplace well-being. Retrieved May 05, 2015, from http://www.ilo.org/safework/areasofwork/ workplace-health-promotion-and-well-being/WCMS_118396/lang--en/index. htm

International Labour Organisation (ILO). (2010, July 06). Recommendation 200: Recommendation concerning HIV and AIDS and the world of work adopted by the Conference at its ninety-ninth Session, Geneva, 17 June 2010. Retrieved May 08, 2015, from http://www.ilo.org/ilc/ILCSessions/99thSession/texts/ WCMS_142613/lang--en/index.htm

Kaplowitz, M.D., Hadlock, T.D., \& Levine, R. (2004). A comparison of web and mail survey response rates. Public Opinion Quarterly, 68, 94-101. http://dx.doi. org/10.1093/poq/nfh006

Kirkham, H.S., Clark, B.L., Bolas, C.A., Lewis, G.H., Jackson, A.S., Fisher, D. et al. (2015) Which modifiable health risks are associated with changes in productivity costs? Population Health Management, 18(1), 30-38. PMID: 25375893, http://dx.doi. org/10.1089/pop.2014.0033

Kuoppala, J., Lamminpää, A., \& Husman, P. (2008). Work health promotion, job wellbeing, and sickness absences--a systematic review and meta-analysis. Journal of Occupational and Environmental Medicine, 50(11), 1216-1227. PMID: 19001948 http://dx.doi.org/10.1097/JOM.0b013e31818dbf92

Linnan, L., Bowling, M., Childress, J., Lindsay, G., Blakey, C., Pronk, S. et al. (2008). Results of the 2004 National Worksite Health Promotion Survey. American Journa of Public Health, 98(8), 1503-1509. PMID: 18048790, http://dx.doi.org/10.2105/ AJPH.2006.100313

Lucini, D., Solaro, N., Lesma, A., Gillet, V.B., \& Pagani, M. (2011). Health promotion in the workplace: Assessing stress and lifestyle with an intranet tool. Journa of Medical Internet Research, 13(4), e88. PMID: 22068357, http://dx.doi. org/10.2196/jmir.1798 
Mail \& Guardian. (2015, April 2). Campaigning for a fourth bottom line. Retrieved May 05, 2015, from http://mg-co za/article/2015-04-02-00-campaigning-for-a-fourthbottom-line/

McFarlin, S.K., \& Fals-Stewart, W. (2002). Workplace absenteeism and alcohol use: A sequential analysis. Psychology of Addictive Behaviours, 16(1), 17-21. PMID: 11934081, http://dx.doi.org/10.1037/0893-164X.16.1.17

Merrill, R.M., Aldana, S.G., Pope, J.E., Anderson, D.R., Coberley, C.R., Vyhlidal, T.P. et al. (2011). Evaluation of a best-practice worksite wellness program in a smallemployer setting using selected well-being indices. Journal of Occupational and Environmental Medicine, 53(4), 448-454. PMID: 21407092, http://dx.doi. org/10.1097/JOM.0b013e3182143ed0

Osilla, K.C., dela Cruz, E., Miles, J.N.V., Zellmer, S., Watkins, K., Larimer, M.E. et al. (2010). Exploring productivity outcomes from a brief intervention for at-risk drinking in an employee assistance program. Addictive Behaviors, 35(3), 194-200. PMID: 19897312, http://dx.doi.org/10.1016/j.addbeh.2009.10.001

Panter, C. (2009). Workplace wellness works. Mercedes Benz. Workshop, Nelson Mandela Bay Business Chamber, Port Elizabeth, South Africa, 29 October 2009.

Parry, C.D., Patra, J., \& Rehm, J. (2011). Alcohol consumption and non-communicable diseases: Epidemiology and policy implications. Addiction, 106(10), 1718-1724. PMID: 21819471, http://dx.doi.org/10.1111/j.1360-0443.2011.03605.x

Rehm, J., Baliunas, D., Borges, G.L.G., Graham, K., Irving, H., Kehoe, T. et al. (2010) The relation between different dimensions of alcohol consumption and burden of disease: An overview. Addiction, 105(5), 817-843. PMID: 2033157, http://dx.doi. org/10.1111/j.1360-0443.2010.02899.x

Rehm, J., Shield, K.D., Joharchi, N., \& Shuper, P.A. (2012). Alcohol consumption and the intention to engage in unprotected sex: Systematic review and meta-analysis of experimental studies. Addiction, 107(1), 51-59. PMID: 22151318, http://dx.doi. org/10.1111/j.1360-0443.2011.03621.x

Rosen, S., Feeley, F., Connelly, P., \& Simon, J. (2007). The private sector and HIV/AIDS in Africa: Taking stock of 6 years of applied research. AIDS, 21(Suppl. 3), S41-S51. PMID: 17666961, http://dx.doi.org/10.1097/01.aids.0000279693.61652.2d

SABCOHA. (2012). SABCOHA: Empowering business in the fight against HIV 2004 to 2012. Flagship report. Retrieved May 08, 2015, from http://www.sabcoha.org/ wp-content/uploads/2013/10/Sabcoha Flagship report FINAL.pdf

Sarna, L., Aguinaga Bialous, S., Wells, M.J., Kotlerman, J., Froelicher, E.S., \& Wewers, M.E. (2009). Do you need to smoke to get a break? Smoking status and missed work breaks among staff nurses. American Journal of Preventive Medicine, 37(Suppl. 2), S165-S171. PMID: 19591757, http://dx.doi.org/10.1016/j.amepre.2009.05.005

Sinanovic, E., \& Kumaranayake, L. (2006a). Quality of tuberculosis care provided in different models of public-private partnerships in South Africa. International Journal of Tuberculosis and Lung Disease, 10(7), 795-801. PMID: 16848343

Sinanovic, E., \& Kumaranayake, L. (2006b). Sharing the burden of TB/HIV? Costs and financing of public-private partnerships for tuberculosis treatment in South Africa. Tropical Medicine \& International Health: TM \& IH, 11(9), 1466-1474. PMID: 16930269, http://dx.doi.org/10.1111/j.1365-3156.2006.01686.x
Sinanovic, E., \& Kumaranayake, L. (2010). The motivations for participation in public-private partnerships for the provision of tuberculosis treatment in South Africa. Global Public Health, 5(5), 479-492. PMID: 19479590, http://dx.doi. Africa. Global Public Health, 5(5),

Stansfeld, S., \& Candy, B. (2006). Psychosocial work environment and mental health - A meta-analytic review. Scandinavian Journal of Work, Environment and Health, 32(6), 443-462. PMID: 17173201, http://dx.doi.org/10.5271/ sjweh.1050

Thurlow, J., Gow, J., \& George, G. (2009). HIV/AIDS, growth and poverty in KwaZuluNatal and South Africa: An integrated survey, demographic and economy-wide analysis. Journal of the International AIDS Society, 12, 1-13. PMID: 19758444 $\mathrm{http}: / / \mathrm{dx}$.doi.org/10.1186/1758-2652-12-18

Torp, S., Grimsmo, A., Hagen, S., Duran, A., \& Gudbergsson, S.B. (2013). Work engagement: A practical measure for workplace health promotion? Health Promotion International, 28(3), 387-396. PMID: 22692482, http://dx.doi. org/10.1093/heapro/das022

UNAIDS. (2011). Nearly 50\% of people who are eligible for antiretroviral therapy now have access to lifesaving treatment. Retrieved May 03, 2015, from http://www. unaids.org/en/resources/presscentre/pressreleaseandstatementarchive/2011/ november/20111121wad2011report/

Van Wyngaardt, M. (2010, February 19). HIV/Aids research study first of its kind in South Africa. Engineering News. Retrieved May 03, 2015, from http://www. engineeringnews.co.za/article/hivaids-research-for-automotive-componentsector-2010-02-19

Van Zyl, G., \& Lubisi, C. (2009). HIV/AIDS in the workplace and the impact on firmefficiency and firm-competitiveness: The South African manufacturing industry as a case study. SA Journal of Human Resource Management, 7(1), 1-14. http:// dx.doi.org/10.4102/sajhrm.v7i1.206

Vass, J., \& Phakathi, S. (2006). Managing HIV in the workplace: Learning from SMEs. Cape Town: HSRC Press.

Verster, J.C., Stephens, R., Penning, R., Rohsenow, D., McGeary, J., Levy, D. et al. (2010) The alcohol hangover research group consensus statement on best practice in alcohol hangover research. Current Drug Abuse Reviews, 3(2), 116-126. PMID: 20712593, http://dx.doi.org/10.2174/1874473711003020116

WHO. (2015). Healthy workplaces: A WHO global model for action. Retrieved May 04 2015, from http://www.who.int/occupational_health/healthy_workplaces/en/

Widanarko, B., Legg, S., Devereux, J., \& Stevenson, M. (2012). Raising awareness of psychosocial factors in the occurrence of low back symptoms in developing countries. Work, 41(Suppl. 1), 5734-5736. PMID: 22317668, http://dx.doi. org/10.3233/WOR-2012-0934-5734

Widanarko, B., Legg, S., Devereux, J., \& Stevenson, M. (2014). The combined effect of physical, psychosocial/organisational and/or environmental risk factors on the presence of work-related musculoskeletal symptoms and its consequences. Applied Ergonomics, 45(6), 1610-1621. PMID: 24934982, http://dx.doi. org/10.1016/j.apergo.2014.05.018 